\title{
Brief
}

\section{Aortic valve replacement in the conscious patient under regional anesthesia without endotracheal intubation}

\author{
Thomas Schachner, MD, ${ }^{a}$ Johannes Bonatti, MD, ${ }^{a}$ Doris Balogh, MD, ${ }^{b}$ Josef Margreiter, MD, ${ }^{b}$ Peter Mair, MD, \\ Günther Laufer, MD, and Günther Putz, MD, ${ }^{\text {b }}$ Innsbruck, Austria
}

See related articles on pages 1204,1394 , and 1401.
From the Departments of Cardiac Surgery ${ }^{\mathrm{a}}$ and Anesthesia and Critical Care Medicine, ${ }^{\mathrm{b}}$ University Hospital, Innsbruck, Austria.

Received for publication June 28, 2002; accepted for publication July 10, 2002.

Address for reprints: Günther Putz, MD, Associate Professor of Anesthesiology and Critical Care Medicine, Dept of Anesthesia and Critical Care Medicine, Innsbruck University Hospital, Anichstrasse 35, 6020 Innsbruck, Austria (E-mail: Guenther.Putz @uibk.ac.at).

J Thorac Cardiovasc Surg 2003;125:1526-7

Copyright ( $\odot 2003$ by The American Association for Thoracic Surgery

$0022-5223 / 2003 \$ 30.00+0$

doi:10.1016/S0022-5223(02)73416-8

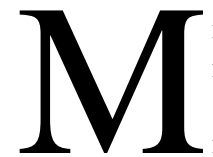

inimally invasive operative procedures are of increasing interest to surgeons, including cardiac surgeons. Aside from the obvious advantage of reducing the surgical trauma, implementation of regional anesthesia is currently under investigation in heart surgery. Our aim was to determine the feasibility of using regional anesthesia without endotracheal intubation in aortic valve replacement with extracorporeal circulation in the conscious patient.

\section{Patient and Methods}

The patient was a 70 -year-old $(171 \mathrm{~cm}, 73 \mathrm{~kg}$ ) man with aortic valve stenosis (mean gradient $55 \mathrm{~mm} \mathrm{Hg}$ ) and hypertension. Preoperative coronary angiography showed no significant coronary artery stenosis. Informed consent was obtained before intervention. Epidural anesthesia was initiated immediately before the operation. The epidural space was located at the C7-T1 level with an 18G Tuohy needle (B. Braun Melsungen AG, Melsungen, Germany) by the hanging drop technique. A 20G catheter (B. Braun Melsungen) was inserted, and analgesia was initiated with bolus injection of $0.75 \%$ ropivacaine $(20 \mathrm{~mL})$ plus sufentanil $(25 \mu \mathrm{g})$ and maintained by continuous infusion of $0.75 \%$ ropivacaine $(5 \mathrm{~mL} / \mathrm{h})$ plus sufentanil $(1 \mu \mathrm{g} / \mathrm{mL})$. Throughout the intervention light sedation was achieved with bolus injections of midazolam (1 $\mathrm{mg}$ total), droperidol (5 mg total), sufentanil ( $5 \mu \mathrm{g}$ total), and propofol (50 mg total). Postoperative analgesia was maintained by continuous infusion of ropivacaine $0.2 \%$ plus sufentanil $(0.5$ $\mu \mathrm{g} / \mathrm{mL}$ ). The patient was monitored in the standard fashion, including repeated blood gas analyses.

The aortic valve was replaced through a median sternotomy. A 30,000-IU dose of heparin was given before cannulation of the aorta with an 8-mm cannula (Stöckert Instrumente $\mathrm{GmbH}$, Munich, Germany). The right atrium was cannulated with a two-stage $36 / 51 \mathrm{~F}$ cannula (Medtronic DLP, Grand Rapids, Mich). Normothermic cardiopulmonary bypass (CPB) flow $\left(2.4 \mathrm{~L} /\left[\mathrm{m}^{2} \times \mathrm{min}\right]\right)$ was achieved, and the aortic valve was replaced with a $23-\mathrm{mm}$ biologic valve (St Jude Medical Inc, Minneapolis, Minn). Buckberg blood cardioplegia in the total amount of $1825 \mathrm{~mL}$ was administered antegrade and retrograde by way of the coronary sinus through a $14 \mathrm{~F}$ catheter (Baxter Healthcare Corporation CardioVascular Group, Irvine, Calif).

\section{Results}

The operation was uneventful. Neural blockade extended from C3 to T8. Operating time was 247 minutes, CPB time was 123 minutes, and aortic crossclamp time was 82 minutes.

Respiratory function before, during, and after $\mathrm{CPB}$ was unimpaired with regard to both spontaneous breathing and gas exchange (Table 1). Hemodynamic condition was stable with moderate use of vasopressors, in particular during extracorporeal circulation. Verbal communication with the patient was possible on demand during CPB. The surgical progress of the procedure was slightly disturbed by the spontaneous breathing pattern. The patient's postoperative course was uncomplicated, and his stay in the intensive care unit was less than 24 hours. 
TABLE 1. Arterial blood gas values during operation

\begin{tabular}{lcc}
\hline & $\mathrm{PaCO}_{\mathbf{2}}(\mathbf{m m ~ H g})$ & $\mathrm{PaO}_{2}(\mathbf{m m ~ H g})$ \\
\hline 30 min before CPB & 52 & $363^{*}$ \\
During CPB & 45 & 348 \\
30 min after CPB & 48 & $280^{*}$
\end{tabular}

*With oxygen at $2 \mathrm{~L} / \mathrm{min}$ by Venturi face mask.

\section{Discussion}

Regional anesthesia in cardiac surgery might be another helpful step toward a less invasive operative procedure. General anesthesia with endotracheal intubation and mechanical ventilation is routinely used and is considered a safe technique. With regional anesthesia, however, intermittent positive-pressure ventilation can be avoided. In particular, spontaneous breathing maintains physiologic intrapulmonary pressures and therefore positively affects pulmonary circulation. Compared with endotracheal intubation, however, full-time monitoring of airway patency is mandatory.

High thoracic epidural anesthesia combined with general anesthesia protects the heart by sympatholysis. Beneficial effects on the perioperative stress response (reduced postoperative heart rate and lower plasma epinephrine levels without jeopardizing cardiac output or perfusion pressure) and on postoperative myocardial ischemia (postoperative troponin $\mathrm{T}$ levels are lower compared with control values) have already been shown. ${ }^{1}$

Additionally, regional anesthesia minimizes the amount of anesthetic drugs required. Under light sedation, the patient feels comfortable and remains conscious throughout the operation. This allows continuous monitoring of brain function, even during CPB.

Because the epidural catheter remains in place for another 3 days after the operation, better pain therapy is possible. This was recently shown by Priestley and colleagues, ${ }^{2}$ who demonstrated that the visual analog pain score was significantly lower in patients receiving epidural analgesia after cardiac surgery.
Thoracic epidural anesthesia without general anesthesia has already been used in off-pump coronary artery bypass surgery and in minimally invasive direct coronary artery bypass surgery. ${ }^{3-5} \mathrm{We}$ have demonstrated that this method is also applicable to aortic valve replacement with $\mathrm{CPB}$.

\section{Conclusion}

This case report shows that regional anesthesia can feasibly be used for aortic valve replacement. Patient comfort is achieved with mild sedation. Intraoperative neurologic monitoring is possible, and impairment of cognitive function by anesthetic drugs is minimized. Cardiac stress is reduced by sympathetic blockade, and pulmonary function remains unimpaired because tracheal intubation and mechanical ventilation are avoided.

\section{References}

1. Loick HM, Schmidt C, Van Aken H, Junker R, Erren M, Berendes E, et al. High thoracic epidural anesthesia, but not clonidine, attenuates the perioperative stress response via sympatholysis and reduces the release of troponin $\mathrm{T}$ in patients undergoing coronary artery bypass grafting. Anesth Analg. 1999;88:701-9.

2. Priestley MC, Cope L, Halliwell R, Gibson P, Chard RB, Skinner M, Klineberg PL. Thoracic epidural anesthesia for cardiac surgery: the effects on tracheal intubation time and length of hospital stay. Anesth Analg. 2002;94:275-82.

3. Vanek T, Straka Z, Brucek P, Widimski P. Thoracic epidural anesthesia for off-pump coronary artery bypass without intubation. Eur J Cardiothorac Surg. 2001;20:858-60.

4. Anderson MB, Kwong KF, Furst AJ, Salerno TA. Thoracic epidural anesthesia for coronary bypass via left anterior thoracotomy in the conscious patient. Eur J Cardiothorac Surg. 2001;20:415-7.

5. Karagoz HY, Sönmez B, Bakkaloglu B, Kurtoglu M, Erdinc M, Türkeli A, et al. Coronary artery bypass grafting in the conscious patient without endotracheal general anesthesia. Ann Thorac Surg. 2000;70:91-6. 